\title{
Infección por SARS-CoV-2 y enfermedad por coronavirus-2019 en pediatría
}

\author{
GUILLERMO ZEPEDA F.*, LORENA TAPIA F.** y PAULA ORTIZ F.***
}

\section{SARS-CoV-2 infection and corona virus disease 2019 in pediatrics}

SARS-CoV-2 infection (and the disease it causes: COVID-19), is less frequent and milder in the pediatric population. The reasons behind this milder clinical expression are under investigation. Nevertheless, children are still susceptible to be infected, to develop symptoms and disease, and to transmit the virus. In this article, we review the information about COVID-19 in children, including epidemiology, etiopathogenesis, diagnostic approach, clinical outcomes and treatment.

Key words: Children; COVID-19; Severe Acute Respiratory Syndrome; coronavirus 2; Pediatrics.

\section{Resumen}

La infección por SARS-CoV-2 (y la enfermedad causada por este virus: COVID-19), es de menor frecuencia y gravedad en pediatría. La naturaleza de esto sigue siendo motivo de análisis. No obstante, los niños tienen la potencialidad de infectarse, enfermarse y de transmitir la infección a otras personas. Este artículo revisa lo conocido hasta el momento acerca de epidemiología, etiopatogenia, cuadro clínico, diagnóstico y tratamiento de COVID-19 en niños. tría.

Palabras clave: Niños; COVID-19; Sindrome Respiratorio Agudo Severo; coronavirus 2; Pedia-

\section{Introducción}

Un nuevo coronavirus ha sido recientemente descrito: SARS-CoV-2. Ante su rápida diseminación, una gran cantidad de publicaciones han aparecido acerca de este agente, con un dinamismo en el conocimiento pocas veces visto en la historia de la medicina. Sin dudas, nuestro entendimiento acerca de la fisiopatología de la infección y sus implicancias seguirá ampliándose. El objetivo de esta revisión es poner en perspectiva lo que conocemos de esta infección en niños.

\section{Epidemiología}

En diciembre de 2019 se notificaron casos de neumonía grave en adultos visitantes o traba- jadores de un mercado de pescados y mariscos ubicado en Wuhan, provincia de Hubei, China. Tras el análisis clínico y microbiológico de los casos y el descarte de otros agentes, se logró aislar un nuevo coronavirus el cual fue secuenciado y denominado SARS-CoV-2 en enero de $2020^{1}$. La infección por este virus causa una enfermedad aguda, principalmente respiratoria, denominada por la Organización Mundial de la Salud (OMS) como COVID-19 (coronavirus disease-2019). El 11 de marzo de 2020, es declarada como pande$\mathrm{mia}^{2}$, afectando hasta fines de abril a más de tres millones de pacientes y acumulándose más de 200.000 muertes $^{3}$.

El primer paciente COVID-19 en Chile fue notificado el 3 de marzo de 2020, tras lo cual ha ocurrido un aumento progresivo de casos, con más de 13.000 pacientes confirmados a la fecha

\footnotetext{
* Neumólogo Pediatra, Departamento de Pediatría y Cirugía Infantil Norte, Facultad de Medicina Universidad de Chile, Hospital Roberto del Río.

** Pediatra, Viróloga, Departamento de Pediatría y Cirugía Infantil Norte y Programa de Virología, ICBM, Facultad de Medicina Universidad de Chile, Hospital Roberto del Río.

*** Intensivista Pediátrico, Hospital Roberto del Río.
} 
de redactar este manuscrito. De estos, un $4,7 \%$ corresponde a menores de 15 años ${ }^{4}$.

\section{Aspectos virológicos de SARS-CoV-2}

Los coronavirus se encuentran ampliamente distribuidos en la naturaleza, infectando a mamíferos, aves y humanos ${ }^{5}$. Desde un reservorio animal (principalmente murciélagos), son capaces de cruzar barreras interespecies, infectando a hospederos intermediarios y finalmente a humanos. Este mecanismo había sido descrito para SARSCoV y MERS-CoV, ambos causantes de epidemias y cuadros pulmonares graves durante los años 2003 y 2012 respectivamente 6 . Algo similar habría ocurrido a fines de 2019, posiblemente en el mercado de pescados y mariscos de Wuhan, provincia de Hubei, China, cuando el nuevo coronavirus SARS-CoV-2 fue capaz de infectar a humanos trabajadores y clientes de dicho lugar ${ }^{7,8}$ (Figura 1).

Los coronavirus son virus envueltos, con genoma ARN de monohebra y polaridad positiva de aproximadamente $30 \mathrm{~kb}$. En su superficie presentan glicoproteínas (spike, o espículas) que le otorgan una morfología característica a la microsco- pía electrónica, similar a una corona ${ }^{5}$. Pertenecen a la familia Coronaviridae, donde se identifican 4 géneros (alfa, beta, gama, delta coronavirus). Con la caracterización de SARS-CoV-2 se han identificado 7 coronavirus humanos. Pertenecen al género beta coronavirus: SARS-CoV, SARSCoV-2, MERS-CoV, HCoV-O43 y HCoV-HKU1. Los coronavirus HCoV-229E y HCoV-NL63 pertenecen al género alfa ${ }^{9}$. Los cuatro últimos coronavirus humanos mencionados son virus endémicos, causantes de infecciones respiratorias altas (tipo resfrío común o enfermedad tipo influenza) y en ocasiones causantes de neumonía ${ }^{5}$.

En cuanto al ciclo replicativo, la adsorción de SARS-CoV-2 se inicia tras la unión de la proteína $\mathrm{S}$ viral a la enzima convertidora de angiotensina 2 (ECA-2) $)^{10,11}$ presente en el epitelio respiratorio y mayormente expresada en el tracto respiratorio bajo. Mediante endocitosis, el virus ingresa a la célula respiratoria, traduciéndose en lisis celular. Este mecanismo de daño, junto a una respuesta inflamatoria variable determinaría la evolución y gravedad de la enfermedad por este agente (COVID-19) ${ }^{12,13}$.

El mecanismo de transmisión principal de SARS-CoV-2 es persona a persona, a través de contacto directo por gotitas que son expulsadas

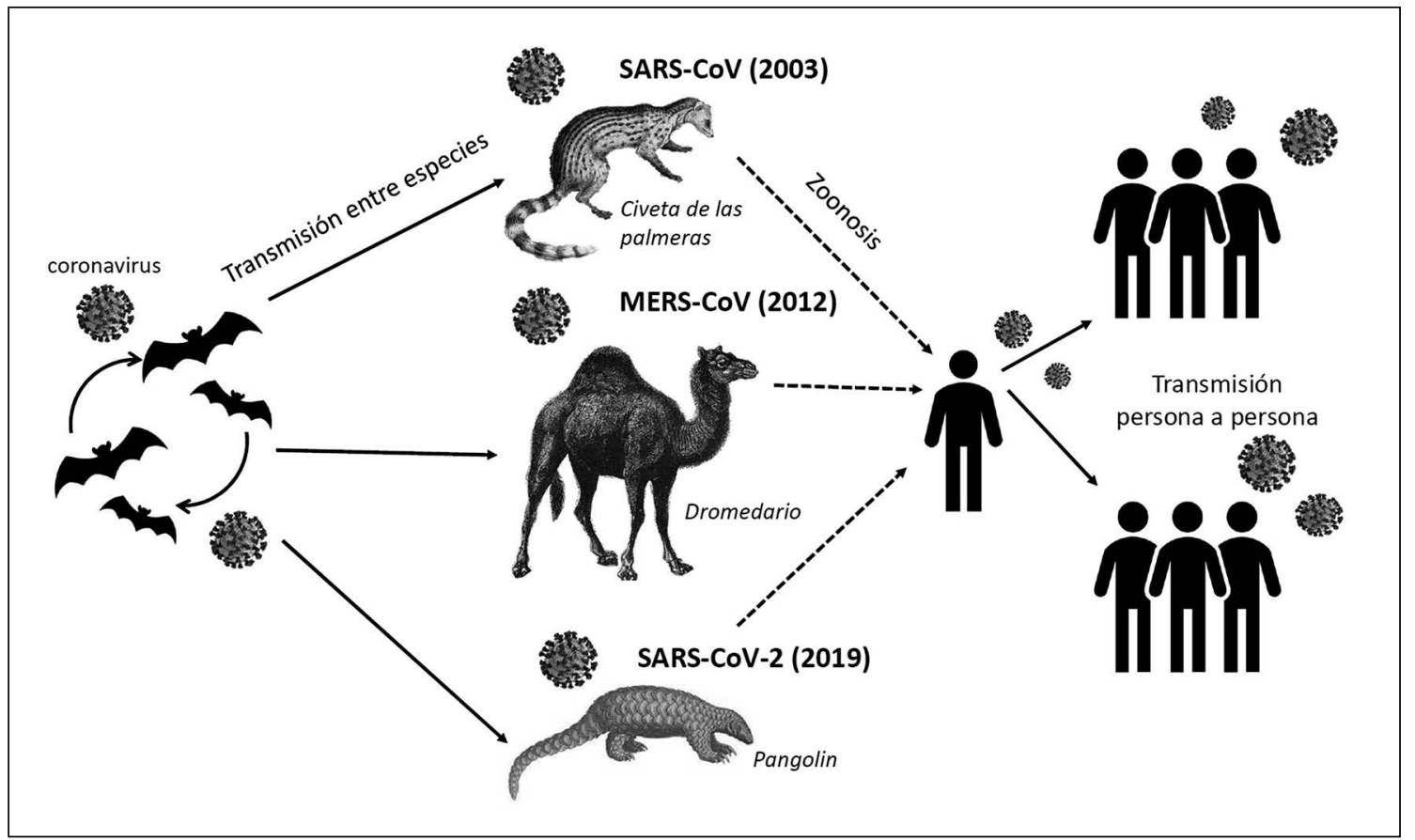

Figura 1. Origen y transmisión de coronavirus SARS-CoV, MERS-CoV, y SARS-Cov-2. Se describe coronavirus en murciélagos como reservorio, luego transmisión entre especias hasta hospederos intermediarios, para finalmente infectar al ser humano, desde donde se perpetúa la expansión a través de una efectiva transmisión persona a persona (Modificado de referencia 6). 
al toser, estornudar o hablar y por fómites. Se ha documentado la excreción viral desde el tracto respiratorio alto y bajo, detectándose genoma viral en altas cargas y aislándose el virus desde muestras respiratorias ${ }^{14,15}$. También se ha detectado genoma viral en deposiciones, en especial en niños ${ }^{16}$. Sin embargo, el virus no ha logrado ser aislado desde ese tipo de muestras ${ }^{15,16}$, por lo que hasta el momento no se demostrado la transmisión fecal oral como un mecanismo plausible en COVID-19.

Experimentalmente se ha descrito una persistencia prolongada del virus en aerosoles (hasta $3 \mathrm{~h})^{17}$, por lo que se postula que la generación aerosoles en procedimientos invasivos como intubación endotraqueal, aspiración de secreciones y toma de exámenes respiratorios en pacientes con infección por SARS-CoV-2 pudiera favorecer la transmisión, en especial al personal de salud. Además se describe una prolongada persistencia del virus en distintas superficies (cobre: $8 \mathrm{~h}$; cartón: $24 \mathrm{~h}$; acero: $24-48$ h; plástico: 72 h) ${ }^{17}$, por lo que se recomienda lavado de manos frecuente $y$ aseo cuidadoso.

\section{Cuadro clínico}

La infección en niños, en la mayoría de los casos, es transmitida desde algún integrante de la familia o cuidador adulto enfermo ${ }^{18-20}$. En general, los niños presentan un cuadro clínico más leve ${ }^{19-23}$, con un período de incubación entre 1 a 14 días (promedio 5-7 días) ${ }^{24}$. Se describen pacientes asintomáticos en frecuencias variables entre 1,3 a $15,8 \%{ }^{19,21,25}$. Esta variabilidad podría deberse a diferencias en el número de pruebas de tamizaje en población general y/o la búsqueda activa de los contactos de pacientes sintomáticos.

En los casos sintomáticos, se describe la presencia de fiebre en 42 a $56 \%$ de los casos y tos en cerca del $50 \%{ }^{21,25,26}$. Otros síntomas descritos son: coriza, disnea, odinofagia, cefalea, fatiga, dificultad para alimentarse, diarrea, náuseas y vómitos $^{20,21,25,26,27}$. Estos síntomas leves pueden infrecuentemente progresar hasta establecerse casos graves, lo que se manifiesta cerca del día 7 de enfermedad ${ }^{28}$. En la Tabla 1 se describen los síndromes clínicos asociados a COVID-19 según la $\mathrm{OMS}^{29}$.

La necesidad de hospitalización es variable, con valores entre 2,9 a $20 \%$ de los casos pediátricos confirmados ${ }^{19,21}$. Se han descrito factores de riesgo de hospitalización: edad menor a 1 año, cardiopatía congénita, patología pulmonar crónica, inmunosupresión, antecedente de prema- turidad al nacer ${ }^{18-20,25,26}$. La necesidad de ingreso a Unidad de Cuidado Intensivo se ha informado como esporádica: $3 / 728(0,4 \%)$ en pacientes confirmados en China ${ }^{21}, 15 / 2572(0,58 \%)$ en EE.UU. ${ }^{19}$ y $2 / 42$ pacientes (4,76\%) en Madrid, España $^{23}$. Del mismo modo, se ha registrado una baja mortalidad en niños, informándose 3 casos letales en EE. UU., dentro de 2.572 casos confirmados ${ }^{19}$ y un paciente fallecido en la provincia de Hubei, China, dentro de 2.135 pacientes pediátricos ${ }^{21}$.

\section{Teorías que explicarían la menor gravedad en niños}

Diferentes series publicadas desde China, Estados Unidos, Italia y España destacan una menor incidencia, prevalencia, menor número de hospitalizaciones, de ingreso a unidades de cuidados intensivos y letalidad en niños ${ }^{19,21-23,27}$. Distintas hipótesis se han planteado para explicar este fenómeno: una respuesta inmune cualitativamente distinta a los adultos ${ }^{18,30}$; presencia de otros virus en vía aérea y pulmones, que podrían limitar el crecimiento de SARS-CoV-2 por competencia e interacción directa ${ }^{30}$; una limitada expresión $y$ funcionalidad de ECA-2 en niños, el cual es el receptor por el cual infecta el SARS-CoV-2 a los órganos diana ${ }^{30}$. Otra explicación sería que los niños son infectados por segunda, tercera o cuarta generación de virus (tras haber infectado previamente a sus contactos adultos), lo cual teóricamente podría disminuir su virulencia ${ }^{18}$. A pesar de lo anterior, los reales mecanismos tras las diferencias clínicas entre adultos y niños permanecen indeterminados.

\section{Diagnóstico etiológico}

El diagnóstico de confirmación COVID-19 se basa en la detección del material genético de SARS-CoV-2 mediante técnicas de amplificación de ácidos nucleicos (TAAN), como la PCR de transcripción reversa en tiempo real ${ }^{31}$. El examen puede ser realizado en distintas muestras respiratorias e incluso desde tejidos, con alta sensibilidad y especificidad ${ }^{32}$. Las muestras nasofaríngeas y orofaríngeas son las más utilizadas, con buen rendimiento durante los primeros días de infección, momento en que las cargas virales en el tracto respiratorio alto son mayores ${ }^{15,33}$, y permitiendo el reconocimiento precoz de los casos. También pueden ser utilizados esputo, aspirado endotraqueal y lavado bronquio-alveolar, lo 
Tabla 1. Síndromes clínicos asociados a COVID-19, según descripción de la OMS ${ }^{29}$

\begin{tabular}{|c|c|}
\hline Enfermedad leve & $\begin{array}{l}\text { Infección respiratoria alta no complicada, pueden tener síntomas inespecíficos como fiebre, tos } \\
\text { seca o productiva, fatiga, rechazo alimentario, dolor muscular, odinofagia, congestión nasal, } \\
\text { menos frecuentemente diarrea, náuseas y vómitos }\end{array}$ \\
\hline \multirow[t]{2}{*}{ Neumonía } & $\begin{array}{l}\text { Diagnóstico clínico de neumonía, pero sin necesidad de oxígeno. Los pacientes tienen tos o } \\
\text { dificultad respiratoria y taquipnea* y sin signos de neumonía severa }\end{array}$ \\
\hline & $*<2$ meses $\geq 60$ RPM; 2 a 11 meses: $\geq 50$ RPM; 1 a 5 años: $\geq 40$ RPM \\
\hline \multirow[t]{2}{*}{ Neumonía severa } & $\begin{array}{l}\text { Tos o dificultad respiratoria más al menos } 1 \text { de los siguientes: } \\
\text { - Cianosis central o } \mathrm{SpO}_{2}<90 \% \text {; } \\
\text { - Dificultad respiratoria severa (por ejemplo, quejido, hundimiento de costillas); } \\
\text { - Signos de neumonía con un signo general de alarma: dificultad para amamantar o para hi- } \\
\text { dratarse, letargia o pérdida de conciencia o convulsiones. Otros signos de neumonía pueden } \\
\text { estar presente: hundimiento de costillas, taquipnea. }\end{array}$ \\
\hline & $\begin{array}{l}\text { Mientras el diagnóstico es realizado por el cuadro clínico, imágenes pulmonares pueden } \\
\text { identificar o excluir algunas complicaciones pulmonares. }\end{array}$ \\
\hline \multirow[t]{4}{*}{$\begin{array}{l}\text { Síndrome de distrés } \\
\text { respiratorio agudo }\end{array}$} & $\begin{array}{l}\text { Inicio: dentro de una semana de iniciado el cuadro clínico o aparición de nuevos síntomas } \\
\text { respiratorios o empeoramiento de los síntomas subyacentes. }\end{array}$ \\
\hline & $\begin{array}{l}\text { Imagenología torácica (radiografía, tomografía computada o ecografía): opacidades bilatera- } \\
\text { les, no totalmente explicada por sobrecarga de volumen, colapso pulmonar o lobar o nódulos. }\end{array}$ \\
\hline & $\begin{array}{l}\text { Origen de infiltrados pulmonares: falla respiratoria no es totalmente explicada por falla } \\
\text { cardíaca o sobrecarga de volumen. Se necesita evaluación objetiva con ecocardiografía para } \\
\text { excluir causa hidrostática de infiltrados/edema si no hay factores de riesgo presentes. }\end{array}$ \\
\hline & $\begin{array}{l}\text { Deterioro de la oxigenación: Usar } \mathrm{PaO}_{2} \text { cuando esté disponible. } \mathrm{Si}_{\mathrm{PaO}} \text { no está disponible, } \\
\text { usar } \mathrm{FiO}_{2} \text { para mantener } \mathrm{SpO}_{2} \leq 97 \% \text { y calcular OSI o } \mathrm{SpO}_{2} / \mathrm{FiO}_{2}(\mathrm{SAFI}) \text {. } \\
\text { - } \mathrm{Bipap}_{\mathrm{O}} \mathrm{CPAP} \geq 5 \mathrm{~cm} \mathrm{H}_{2} \mathrm{O} \text { vía máscara facial completa: } \mathrm{PaO}_{2} / \mathrm{FiO}_{2} \leq 300 \mathrm{mmHg} \text { o SpO} 2 / \\
\mathrm{FiO}_{2} \leq 264 \mathrm{mmHg} \\
\text { - } \mathrm{SDRA} \text { leve (ventilado invasivamente): } 4 \leq \mathrm{OI}<8 \text { o } 5 \leq \mathrm{OSI}<7,5 \\
\text { - } \text { SDRA moderado (ventilado invasivamente): } 8 \leq \mathrm{OI}<16 \text { o } 7,5 \leq \mathrm{OSI}<12,3 \\
\text { - } \text { SDRA severo (ventilado invasivamente): } \mathrm{OI} \geq 16 \text { o OSI } \geq 12,3\end{array}$ \\
\hline Sepsis & $\begin{array}{l}\text { Infección confirmada o sospechada } \mathrm{y} \geq 2 \text { criterios de síndrome de respuesta inflamatoria } \\
\text { sistémica de los cuales uno debe ser alteración de la temperatura o del recuento leucocitario }\end{array}$ \\
\hline Shock séptico & $\begin{array}{l}\text { Cualquier hipotensión (PAS }<\text { p5 o }>2 \text { DS bajo lo normal para la edad) o } 2 \text { o } 3 \text { de los siguien- } \\
\text { tes parámetros: estado mental alterado, taquicardia o bradicardia (FC }<90 \text { LPM o }>160 \text { LPM } \\
\text { en lactantes y FC }<70 \text { LPM o }>150 \text { LPM en niños): llene capilar prolongado ( }>2 \text { segundos) } \\
\text { o pulso débil; taquipnea; piel fría o moteada o rush purpúrico o petequial; lactato elevado; } \\
\text { oliguria; hipertermia o hipotermia }\end{array}$ \\
\hline
\end{tabular}

Abreviaturas: $\mathrm{RPM}=$ respiraciones por minuto. $\mathrm{SpO}_{2}=$ saturación de oxígeno. $\mathrm{OI}=$ índice de oxigenación. OSI $=$ índice de oxigenación usando $\mathrm{SpO}_{2} . \mathrm{PaO}_{2}=$ presión arterial de oxígeno. $\mathrm{FiO}_{2}=$ fracción inspirada de oxígeno. SDRA = síndrome de distrés respiratorio agudo. $\mathrm{PAS}=$ presión arterial sistólica. $\mathrm{P}=$ percentil. $\mathrm{DS}=$ desviación estándar. $\mathrm{FC}=$ frecuencia cardíaca. LPM = latidos por minuto.

cual es recomendado en pacientes con neumonía y TAAN negativa desde muestra de tracto respiratorio alto ${ }^{15}$, situación más frecuente en adultos.

Otra aproximación diagnóstica para $\mathrm{CO}$ VID-19 se basa en pruebas serológicas, las que buscan detectar la presencia de anticuerpos de tipo IgM e IgG anti-SARS-CoV-2 en sangre ${ }^{31,34}$. Se han desarrollado pruebas basadas en técnica de ELISA y de inmunocromatografía ${ }^{32}$, siendo esta última técnica fácil de aplicar, sin necesidad de un laboratorio especializado. Debido a que la respuesta humoral tarda en promedio 7 a 11 días en desarrollarse, este tipo de exámenes se reserva para pacientes con historia prolongada de síntomas, o para establecer retrospectivamente la tasa de ataque que mostró el virus en una determinada población. Puede ser útil en pacientes sospechosos que presentan un estudio molecular negativo y que presentan más de 5 días de síntomas.

Una tercera aproximación es mediante la detección de antígeno SARS-CoV-2 por medio de pruebas rápidas, que detectan componentes estructurales del virus (proteína $\mathrm{S}$, proteína $\mathrm{N}$ ) presentes en muestras de secreción nasofaríngea durante etapas tempranas de la infección ${ }^{34,35}$. Se propone como prueba rápida, simple y menos costosa para diagnosticar tempranamente a personas infectadas. Sin embargo, se necesitan más estudios que analicen la sensibilidad y especificidad de esta prueba. 


\section{Laboratorio}

Además del diagnóstico etiológico, distintos exámenes de laboratorio complementan el estudio y manejo de los pacientes COVID-19, en especial en pacientes hospitalizados por cuadros graves. La utilidad de estos estudios se basa en: descartar infecciones concomitantes, evaluar grado de hipoxia en casos con sospecha de discordancia gasométrico-clínica, determinar compromiso de series hematológicas (en especial trombocitopenia, leucopenia y linfopenia), evaluar posible compromiso hepático y renal y detectar tempranamente inflamación exagerada y eventos trombóticos. Todos estos, son eventos que se han asociado a mayor gravedad en adultos, por lo que su detección temprana podría mejorar el pronóstico ${ }^{8,36}$ (Tabla 2).

\section{Radiología}

El estudio de imágenes no está recomendado de rutina en pacientes pediátricos con COVID-19. Se sugiere complementar con radiografía de tórax o bien tomografía computarizada (TC) en casos de empeoramiento clínico, sospecha de neumonía y en especial ante sospecha de complicaciones. En etapas tempranas de la infección se han descrito múltiples sombras pequeñas irregulares y cambios intersticiales en la periferia pulmonar en radiografía de tórax ${ }^{28}$. Estudios con TC han detectado lesiones pulmonares incluso en pacientes asintomáticos y casos leves. Se describen lesiones pulmonares uni o bipulmonares, lesiones subpleurales con infiltrado inflamatorio localizado, condensación pulmonar con signo del halo, imágenes en vidrio esmerilado e imágenes nodulares pequeñas ${ }^{37}$.

\section{Manejo clínico según estado clínico}

La atención de los pacientes se debe ajustar a la gravedad y la presencia de factores de riesgo al momento de consultar, junto con la implementación de medidas para prevenir infecciones dentro del personal de salud y familiares.

Los casos leves no requieren hospitalización, a excepción de casos con factores de riesgo social que imposibiliten una adecuada vigilancia y aislamiento. Se aconseja el manejo ambulatorio con tratamiento sintomático, utilizando paracetamol como primera línea en caso de fiebre. Indicar los síntomas y signos de alarma, ante los que deben consultar nuevamente. Entregar también las recomendaciones para evitar la transmisión

Tabla 2. Exámenes complementarios en estudio de pacientes COVID-19

- Estudio de virus respiratorios: Inmunofluorescencia
o panel molecular según disponibilidad, sospecha y
gravedad del paciente
- Hemograma - PCR
- Gases en sangre arterial
- Electrolitos plasmáticos
- Creatinina, nitrógeno ureico
- Transaminasas
- LDH, creatinincinasas, Dímero D
- Ferritina, fibrinógeno, triglicéridos
- Pruebas de coagulación

Abreviaturas $=$ PCR: proteína $\mathrm{C}$ reactiva. $\mathrm{LDH}$ : lactatodeshidrogenasa.

intradomiciliaria, incluyendo utilización de mascarillas $^{38-40}$.

Se deben hospitalizar los pacientes que tengan neumonía más factores de riesgo y aquellos con cuadros graves (Tabla 1). Se consideran factores de riesgo: menores de 1 año, prematuridad, cardiopatía congénita, daño pulmonar crónico, inmunodeficiencia, insuficiencia renal crónica, enfermedad metabólica ${ }^{41}$. Considerar también los casos en riesgo social, cuando no se pueda asegurar cuidados, aislamiento y controles adecuados.

Se recomienda hospitalización en box de aislamiento, idealmente con flujo de aire a presión negativa. Si no se cuenta con box individual, la hospitalización en cohorte es posible. Es aconsejable que se establezcan y organicen anticipadamente las áreas específicas para el manejo de pacientes COVID-19 de manera de optimizar el flujo de personal de salud y el uso de los equipos de protección personal (EPP) ${ }^{42}$.

Ante el manejo de pacientes COVID-19 se recomienda tanto evitar el retraso en los tratamientos más apropiados como minimizar los efectos adversos de las terapias, particularmente para pacientes de bajo riesgo ${ }^{43}$.

\section{Enfermedad leve o neumonía no grave}

La mayoría de estos pacientes se manejarán ambulatoriamente. Se hospitalizarán los casos con factores de riesgo.

Se recomienda monitorización no invasiva, principalmente con oximetría. Aporte de oxígeno para lograr oximetría $>93 \%$. Instalación de una vía venosa periférica. Seguimiento radiológico y exámenes complementarios en caso de deterioro clínico. Se debe tener especial atención en los 
pacientes con comorbilidades. Si el paciente presenta deterioro del patrón respiratorio, se recomienda traslado a UCI, para un monitoreo más estrecho ${ }^{39,44}$.

El uso de broncodilatadores no ha demostrado beneficio. Sin embargo, debe considerarse en pacientes con hiperreactividad pulmonar, síndrome bronquial obstructivo recurrente y asma. $\mathrm{Su}$ administración debe realizarse por dispositivo de dosis medida (MDI) por aerocámara o por conexión ad-hoc a circuito de ventilación mecánica, evitándose el uso de nebulizaciones por la posibilidad de formación de aerosoles $\mathrm{s}^{45,46}$.

Se recomienda buscar activamente una coinfección viral o bacteriana, principalmente si persiste fiebre. Controlar con imágenes de tórax, hemograma, hemocultivo, proteína $\mathrm{C}$ reactiva, procalcitonina, transaminasas, electrolitos y coagulación ${ }^{38-40}$ e iniciar antibióticos de forma empírica en caso de alta sospecha ${ }^{39,44}$.

Respecto a la lactancia materna, no se ha detectado presencia de virus en la leche de madres con SARS-CoV-2 ${ }^{47}$. Si se decide mantener la lactancia, se debe entrenar a la madre en uso de mascarilla y lavado de manos ${ }^{48}$.

Se debe contemplar la posibilidad de que los padres puedan ingresar junto al menor, idealmente sólo una persona, siempre la misma. Considerar el uso de las medidas de higiene y protección personales, por lo que cada institución debe ajustar sus protocolos a la realidad local ${ }^{42,49}$.

\section{Neumonía grave}

Requieren ingreso a unidad de cuidados intermedio aquellos pacientes en los que se identifica precozmente la insuficiencia respiratoria hipoxémica, que no responde a terapia de oxígeno estándar, de manera de planificar la necesidad de soporte ventilatorio avanzado ${ }^{38}$. Aquellos casos con requerimientos de oxígeno elevados y aumento de trabajo respiratorio leve se recomienda uso de naricera de alto flujo (HFNO). En niños mayores, según tolerancia se puede colocar una mascarilla (considerar recambio) o utilizar dispositivo Hood en lactantes, para evitar dispersión de aerosoles. La ventilación mecánica no invasiva (VMNI) se puede utilizar en pacientes con mayor trabajo respiratorio y requerimientos de oxígeno. Para este último tipo de terapia se aconseja utilizar interfase facial completa (fullface). En circuitos de una rama, utilizar codo sin válvula espiratoria (codo azul), conectar a pieza en $T$ para adicionar filtro viral-bacteriano para disminuir dispersión de aerosoles, en caso de desconexión de circuito o realizar aseo y confort, dejar equipo en pausa ${ }^{44,45}$.

Estos métodos de soporte ventilatorio deben vigilarse en forma estricta en cuanto a respuesta y tolerancia, considerando además que la enfermedad puede progresar en forma abrupta. Se recomienda evaluar la respuesta en un período de $1 \mathrm{a} 2 \mathrm{~h}$, esperando una reducción de frecuencia cardíaca y respiratoria de al menos $10-20 \%$, reducción de $\mathrm{FiO}_{2}$ a menos de 0,5 y mejoría de la oximetría ${ }^{50}$. Inicialmente estaban en discusión ambos métodos por la posibilidad de dispersión de aerosoles, pero actualmente se recomienda mantener distancias de $2 \mathrm{~m}$ (mínimo $1 \mathrm{~m}$ ) y uso óptimo de EPP. La aspiración de secreciones y terapia kinésica debe ser ajustada a lo estrictamente necesario ${ }^{44,45}$.

\section{Síndrome de distrés respiratorio agudo o enfermedad crítica}

Se considerará ingreso a UCI si el paciente presenta infección de vía aérea baja con criterios de gravedad, o con manifestaciones extrapulmonares asociadas a evolución grave y/o presenta deterioro progresivo ${ }^{39}$.

En cuadros con hipoxemia grave, la intubación endotraqueal y la ventilación mecánica invasiva no debe retardarse. La intubación debe ser realizada por el profesional más experimentado, con secuencia rápida de intubación pre-oxigenando con mascarilla de no recirculación al $100 \%$ por 5 min, evitando utilizar bolsa y máscara. En caso de necesitar utilizarlo, realizarlo a 4 manos y con filtro de alta eficiencia entre la máscara y la bolsa. Seleccionar tubos endotraqueales (TET) con balón (cuff) para evitar fugas, evitar forzar por riesgo de lesión traqueal, usar conductor de tubo y video-laringoscopio para asegurar procedimiento al primer intento, inflar el balón una vez que pase el tubo $2 \mathrm{~cm}$ por debajo de las cuerdas vocales, la presión del balón debe ser $<25 \mathrm{~cm} \mathrm{H}_{2} \mathrm{O}$. Se recomienda la aspiración de secreciones mediante circuito cerrado, uso de material desechable (bolsa de reanimación, circuito de ventilación mecánica). Deben permanecer en sala el mínimo de personas necesarias para el procedimiento, emplear mascarillas FFP 3, antiparras, escudo facial y el resto de las medidas de EPP ${ }^{51,52}$. Pueden ser de utilidad los boxes de intubación de acrílico ${ }^{53}$. Especial atención se debe considerar al retiro de los EPP dado el alto riesgo de contaminación en este proceso.

La simulación es una herramienta que puede contribuir a la optimización de estructuras de trabajo y este tipo de procesos ${ }^{54}$, por lo que es recomendable considerarla como una herramienta de aprendizaje dentro de los equipos de salud, ayudando a través de la práctica a disminuir el número de errores y riesgo de contagio del personal. 


\section{Tabla 3. Descripción de medicamentos utilizados en COVID-19}

\begin{tabular}{|c|c|}
\hline Medicamento & Descripción \\
\hline $\begin{array}{l}\text { Hidroxicloroquina y } \\
\text { cloroquina }^{40,41,44,60}\end{array}$ & $\begin{array}{l}\text { Antipalúdico, antiinflamatorio usado en enfermedades autoinmunes } \\
\text { Es de las terapias más utilizadas actualmente como terapia específica. Su efecto antiviral se } \\
\text { presume a través de bloqueo de la entrada a la célula, elevando el } \mathrm{pH} \text { del endosoma, previ- } \\
\text { niendo la fusión. Reportes de su uso en China demuestran negativización de la carga viral, } \\
\text { acortando el curso de la enfermedad, pero falta más evidencia para recomendar su uso. El } \\
\text { perfil de seguridad clínica de hidroxicloroquina es mejor que el de cloroquina y permite una } \\
\text { dosis diaria más alta } \\
\text { Posible efecto adverso: prolongación del intervalo QT del ECG con riesgo de arritmias graves } \\
\text { y muerte. Se sugiere monitorización }\end{array}$ \\
\hline $\begin{array}{l}\text { Lopinavir-Ritonavir } \\
\left(\text { Kaletra }^{\circledR}\right)^{39,40,44}\end{array}$ & $\begin{array}{l}\text { Inhibidor de proteasa viral, que se utiliza en tratamiento de la infección por VIH. Se planteó } \\
\text { su utilidad in vitro frente a coronavirus. Sin embargo, no existen estudios aleatorizados que } \\
\text { demuestren su utilidad. Se describen síntomas gastrointestinales al inicio del tratamiento } \\
\text { como diarrea y vómitos }\end{array}$ \\
\hline Remdesivir $^{39,40}$ & $\begin{array}{l}\text { Antiviral desarrollado para el tratamiento del virus ébola. En estudios animales infectados con } \\
\text { MERS-CoV reducen los títulos de virus y mejora el daño pulmonar. Recientemente aprobado } \\
\text { por la FDA (Food and Drug Administration, USA) para el tratamiento de casos graves. No } \\
\text { está disponible en Chile }\end{array}$ \\
\hline Interferón alfa ${ }^{38-40,44}$ & $\begin{array}{l}\text { Puede disminuir la carga viral en la etapa precoz, aliviar los síntomas y acortar la enfermedad } \\
\text { en algunas infecciones virales. Se describen como efectos secundarios: alteración hematológi- } \\
\text { ca, hepática y alteración del crecimiento en niños y adolescentes por lo que no se recomienda } \\
\text { su uso en pacientes pediátricos }\end{array}$ \\
\hline Azitromicina ${ }^{40,44,60}$ & $\begin{array}{l}\text { Antibiótico con capacidad inmunomoduladora, la que podría ser útil en COVID-19 asociado } \\
\text { a Hidroxicloroquina, pero falta mayor evidencia que avale su uso. Se asocia a prolongación } \\
\text { del intervalo QT }\end{array}$ \\
\hline Tocilizumab $^{40,41}$ & $\begin{array}{l}\text { Anticuerpo monoclonal IgG1 recombinante humanizado anti receptor de Interleuquina } 6 \text { (IL- } \\
\text { 6). En relación con pacientes infectados, críticamente enfermos se describe una "tormenta de } \\
\text { citoquinas" asociado a *SDRA, en este caso se podría considerar su uso. Considerar medición } \\
\text { de ferritina, PCR, recuento de linfocitos (linfopenia), niveles de IL-6 si está disponible }\end{array}$ \\
\hline $\begin{array}{l}\text { Inmunoglobulina } \\
\text { endovenosa }\end{array}$ & $\begin{array}{l}\text { En casos graves asociado a respuesta inflamatoria descontrolada. Su eficacia en COVID-19 } \\
\text { necesita futuras evaluaciones }\end{array}$ \\
\hline Corticoides $^{38,39,4144}$ & $\begin{array}{l}\text { No está recomendado su uso, en especial en períodos precoces de la enfermedad. En estudios } \\
\text { sobre su utilidad en MERS-CoV, Influenza no han mostrado efectos benéficos e incluso retraso } \\
\text { del aclaramiento de virus. Se puede valorar en shock séptico refractario, encefalitis, síndrome } \\
\text { hemofagocítico y en pacientes con asma o SBOR previo }\end{array}$ \\
\hline
\end{tabular}

Abreviaturas: SDRA: síndrome de distrés respiratorio agudo. SBOR: síndrome bronquial obstructivo recurrente.

La ventilación mecánica debe ajustarse a un concepto de ventilación mecánica protectora y recomendaciones para manejo de SDRA en pediatría, evitando así lesión secundaria. Se deben utilizar volúmenes corrientes entre $4-8 \mathrm{ml} / \mathrm{kg}$ de peso ideal, limitar la presión plateu o meseta a $<28-30 \mathrm{~cm} \mathrm{H}_{2} \mathrm{O}$, presión diferencial o driving pressure $<15 \mathrm{~cm} \mathrm{H}_{2} \mathrm{O}$, hipercapnia permisiva, seleccionar la presión de final de espiración (PEEP) según potencial de reclutamiento y mejor compliance $^{55}$.

La ventilación de alta frecuencia oscilatoria, puede ser una alternativa para manejo de SDRA en pediatría y de escape aéreo, pero se debe considerar la posibilidad de eliminación de aerosoles a través de sus válvulas ${ }^{44,56}$.

En SDRA de adulto se reportan dos fenotipos distintos de presentación: H y L. En el primero destaca un compromiso pulmonar con elastancia elevada (compliance baja), 20-30\% de los casos, aumento del shunt y alto potencial de reclutamiento. En el fenotipo L se observa una compliance cercana a lo normal, la hipoxemia se podría explicar por la pérdida de la regulación vascular pulmonar. En este caso, la PEEP alta puede tener efectos perjudiciales sobre la hemodinamia. El aumento del trabajo respiratorio $\mathrm{y}$ las variaciones de la presión pleural negativa, pueden ser los determinantes de la transición del fenotipo $\mathrm{L}$ al $\mathrm{H}^{57}$. En relación con esto, se recomienda uso racional de bloqueo neuromuscular ${ }^{56}$ para evitar las presiones transpulmonares altas y disincronías.

La ventilación en prono puede ser utilizada en caso de hipoxemia refractaria: si a las 4-6 h no se logra mantener ventilación protectora y mejoría 
en la oxigenación ${ }^{39,51,56}$. Se reporta la mejoría de la oxigenación incluso en pacientes que sólo utilizan oxigenoterapia. Los períodos de permanencia en prono no están determinados en forma precisa, pero se utilizan rangos de 12 a $18 \mathrm{~h}$ y períodos prolongados de hasta $72 \mathrm{~h}$. Otros grupos recomiendan alternancia prono-supino. Sin embargo, se debe considerar la demanda que significa para el equipo de enfermería, riesgo de aerosolización, y riesgo de lesiones de la piel por apoyo.

Se puede intentar terapia con óxido nítrico cuando se sospecha hipoxia refleja por vasoconstricción pulmonar, con compliance normal y no hay mejoría con las otras terapias mencionadas anteriormente ${ }^{56}$.

Considerar soporte de membrana de oxigenación extracorpórea (ECMO) en aquellos pacientes con hipoxemia refractaria a VMI protectora, prono, óxido nítrico, shock séptico, shock cardiogénico secundario a COVID-19, falla orgánica única (AKI: acute kidney injury, no se considera contraindicación) y presencia comorbilidades menores $^{38,58}$. Se debe sopesar la situación epidemiológica y la factibilidad técnica en cuanto a recursos humanos y costos asociados a la terapia ${ }^{56}$.

Es recomendable minimizar las exploraciones complementarias durante el manejo. En imágenes como radiografías y ecografías se recomiendan equipos portátiles dentro de la unidad del paciente, considerar precauciones en el manejo y desinfección especial. Para el traslado de pacientes hacia exámenes como resonancia magnética, tomografía computada o pabellón, se deben implementar medidas específicas de traslado, aseo $\mathrm{y}$ desinfección de equipos ${ }^{38,42}$.

\section{Complicaciones}

El manejo tanto del SDRA grave, sepsis o disfunción multiorgánica no difiere en forma significativa de lo recomendado para estos pro$\operatorname{cesos}^{39}$. Pueden aparecer signos de shock y falla miocárdica ${ }^{20,59}$. La reanimación con volumen debe ser cuidadosa, como se mencionó previamente. El soporte con drogas vasoactivas debe realizarse en base a las recomendaciones internacionales pediátricas (Surviving sepsis campaign), y uso de antibióticos dentro de la primera hora del diagnóstico.

\section{Terapia específica}

No existen antivirales específicos que hayan demostrado utilidad en infecciones virales, coronavirus humanos, SARS-CoV o MERS-CoV. Sin embargo, dado el contexto de pandemia se han probado distintas terapias de manera experimental $^{38,39,41,59}$. En la Tabla 3 se detallan algunos de los medicamentos planteados como alternativas hasta el momento, no existiendo a la fecha un nivel de evidencia que justifique indiscutiblemente su uso $^{38-41,56,58-60}$.

\section{Criterios de alta}

A nivel internacional se han establecido los criterios de alta de niños hospitalizados: afebril por al menos 2 a 3 días, mejoría de sintomatología respiratoria, (gasometría arterial normal) sin requerimientos de $\mathrm{O}_{2}$ adicional, normalización de exámenes de laboratorio, imágenes pulmonares hacia la mejoría. En los casos graves, la mejoría clínica puede complementarse con dos pruebas de PCR negativas para SARS-CoV-2 desde muestras respiratorias separadas con al menos $24 \mathrm{~h}$ de diferencia ${ }^{24,28}$.

\section{Seguimiento posterior al alta}

Se sugiere aislamiento en casa por 14 días posterior al alta, después de la resolución de fiebre y síntomas respiratorios. Se recomienda: uso de mascarilla si persiste la tos, control de temperatura 2 veces al día (consultar en caso de presentar fiebre), pieza aislada bien ventilada, evitando el contacto con miembros de la familia, alimentación y lavado de utensilios en forma separada, lavado de manos frecuentes. Evitar las visitas y salir del hogar ${ }^{24}$.

Se recomienda regresar al hospital para control y seguimiento 2 a 4 semanas posterior al alta ${ }^{24}$. Se adelantará el control a los 7 días en los casos en que al alta se encontraran con radiografía de tórax, hemograma u otro examen alterado. Notificar el alta y su condición clínica epidemiológica a la SEREMI de Salud correspondiente para seguimiento.

\section{Bibliografía}

1.- ZHU N, ZHANG D, WANG W, LI X, YANG B, SONG J, et al. A novel coronavirus from patients with pneumonia in China, 2019. N Engl J Med 2020; 382: 727-33. Disponible en: https://doi.org/10.1056/NEJMoa2001017.

2.- WHO. Coronavirus disease 2019 (COVID-19). Situation Report 51 (11.03.2020), Disponible en: https:/www.who.int/docs/default-source/coronaviruse/situation-reports/20200311-sitrep-51-covid-19. pdf?sfvrsn=1ba62e57_10 (Accedido el 1 de mayo de 2020).

3.- WHO. Coronavirus disease 2019 (COVID-19). Situation Report 101 (30.04.2020), Disponible en: https:// www.who.int/docs/default-source/coronaviruse/ 
situation-reports/20200430-sitrep-101-covid-19. pdf?sfvrsn=2ba4e093_2 (Accedido el 1 de mayo de 2020).

4.- DEPARTAMENTO DE EPIDEMIOLOGÍA. MINISTERIO DE SALUD. Duodécimo informe epidemiológico. Enfermedad por SARS COV 2 (COVID-19). 28.04.2020, Disponible en: https:/www.minsal.cl/ wp-content/uploads/2020/04/Informe-EPI-27042020. pdf (Revisado: 1 de mayo de 2020)

5.- FEHR AR, PERLMAN S. Coronaviruses: An Overview of Their Replication and Pathogenesis. In: Maier HJ, Bickerton E \& Britton P, editors. Coronaviruses. Methods and Protocols. New York: Springer Science+Business Media New 2015. p. 1-25.

6.- DE WIT E, VAN DOREMALEN N, FALZARANO D, MUNSTER VJ. SARS and MERS: Recent insights into emerging coronaviruses. Nature Rev Microbiol 2016; 14: 523-34. Disponible en: https://doi. org/10.1038/nrmicro.2016.81.

7.- WU F, ZHAO S, YU B, CHEN Y-M, WANG W, SONG Z-G, et al. A new coronavirus associated with human respiratory disease in China. Nature 2020, January. Disponible en: https://doi.org/10.1038/s41586020-2008-3.

8.- ZHOU P, YANG X-L, WANG X-G, HU B, ZHANG L, ZHANG W, et al. A pneumonia outbreak associated with a new coronavirus of probable bat origin. Nature 2020; 579: 270-3. Disponible en: https://doi. org/10.1038/s41586-020-2012-7.

9.- CHAN JFW, LAU SKP, TO KKW, CHENG VCC, WOO PCY, YUE KY. Middle East Respiratory syndrome coronavirus: Another zoonotic betacoronavirus causing SARS-like disease. Clin Microbiol Rev 2015; 28: 465-522. Disponible en: https://doi.org/10.1128/ CMR.00102-14.

10.- OU X, LIU Y, LEI X, LI P, MI D, REN L, et al. Characterization of spike glycoprotein of SARS-CoV-2 on virus entry and its immune cross-reactivity with SARSCoV. Nature Communications 2020, 11. Disponible en: https://doi.org/10.1038/s41467-020-15562-9.

11.- YAN R, ZHANG Y, LI Y, XIA L, GUO Y, ZHOU Q. Structural basis for the recognition of the SARSCoV-2 by full-length human ACE2. Science 2020; 2 : 1444-8. Disponible en: https://doi.org/10.1126/science. abb2762.

12.- LIN L, LU L, CAO W, LI T. Hypothesis for potential pathogenesis of SARS-CoV-2 infection-a review of immune changes in patients with viral pneumonia. Emerging Microbes \& Infections 2020; 1751: 1-14. Disponible en: https://doi.org/10.1080/22221751.2020. 1746199.

13.- PROMPETCHARA E, KETLOY C, PAlAGA T. Immune responses in COVID-19 and potential vaccines: Lessons learned from SARS and MERS epidemic. Asian Pacific J Allergy Immunol 2020. Disponible en: https://doi.org/10.12932/AP-200220-0772.
14.- LEUNG NHL, CHU DKW, SHIU EYC, CHAN KH, et al. Respiratory Virus Shedding in Exhaled Breath and Efficacy of Face Masks. Nature Med 2020. Disponible en: https://doi.org/10.1038/s41591-020-0843-2.

15.- WÖLFEL R, CORMAN VM, GUGGEMOS W, SEILMAIER M, ZANGE S, MÜLLER MA, et al. Virological assessment of hospitalized patients with COVID-2019. Nature 2020. Disponible en: https://doi. org/10.1038/s41586-020-2196-X.

16.- XU Y, LI X, ZHU B, LIANG H, FANG C, GONG $\mathrm{Y}$, et al. Characteristics of pediatric SARS-CoV-2 infection and potential evidence for persistent fecal viral shedding. Nature Med 2020, 1-4. Disponible en: https:// doi.org/10.1038/s41591-020-0817-4.

17.- VAN DOREMALEN N, BUSHMAKER T, MORRIS D, HOLBROOK M, GAMBLE A, WILLIAMSON B. Aerosol and Surface Stability of SARS-CoV-2 as Compared with SARS-CoV-1. N Engl J Med 2020. Disponible en: https://doi.org/10.1056/NEJMc2004973.

18.- SU L, MA X, YU H, ZHANG Z, BIAN P, HAN Y, et al. The different clinical characteristics of corona virus disease cases between children and their families in China - the character of children with COVID 19. Emerging Microbes \& Infections 2020; 9: 707-13.

19.- BIALEK S, GIERKE R, HUGHES M, MCNAMARA L, PILISHVILI T, SKOFF T. Coronavirus disease 2019 in children - United States, February 12 - April 2, 2020. MMWR 2020; 69 (14): 422-6.

20.- QIU H, WU J, LUO Y, SONG Q, CHEN D. Clinical and epidemiological features of 36 children with coronavirus disease 2019 (COVID-19) in Zheijiang, China: an observational cohort study. Lancet Infec Dis 2020; 20: 689-96. Disponible en: https://doi.org/10.1016/ S1473-3099(20)30198-5.

21.- DONG Y, MO Y, HU Y, QI X, JIANG F, JIANG Z, et al. Epidemiology of COVID-19 among children in China. Pediatrics 2020; 145 (6): e20200702.

22.- PILISHVILI T, RAZZAGHI H, REED N, RITCHEY M, SAUBER-SCHATZ E. Severe outcomes among patients with coronavirus disease 2019 (COVID 19)United States, February 12 - March 16, 2020. MMWR 2020; 69 (12): 343- 6.

23.- TAGARRO A, EPALZA C, SANTOS M, SANZSANTAEUFEMIA FJ, OTHEO E, MORALEDA $\mathrm{C}$, et al. Screening and severity of coronavirus disease 2019 (COVID-19) in children in Madrid, Spain. JAMA Pediatrics 2020 April 8. doi: 10.1001/jamapediatrics.2020.1346. [Epub ahead of print].

24.- NATIONAL HEALTH COMMISSION \& STATE ADMINISTRATION OF TRADITIONAL CHINESE. Diagnosis and treatment protocol for novel coronavirus pneumonia (Trial versión 7). March 3, 2020. Disponible en: https://www.chinadaily.com.cn/ pdf/2020/1.Clinical.Protocols.for.the.Diagnosis.and. Treatment.of.COVID-19.V7.pdf (accedido el 3 de mayo de 2020). 
25.- LU X, ZHANG L, DU H, ZHANG J, LI YY, QU J, et al. SARS-CoV-2 infection in children. N Engl J Med 2020; 382 (17): 1663-5.

26.- ZHENG F, LIAO CH, FAN Q, CHEN H, ZHAO X, XIE Z, et al. Clinical characteristics of children with coronavirus disease 2019 in Hubei, China. Current Medical Science 2020; 40 (2): 1-6.

27.- PARRI N, LENGE M, BUONSENSO D. Children with Covid-19 in Pediatric. Emergency Departments in Italy. N Engl J Med 2020. Disponible en: https://doi. org/10.1056/NEJMc2007617.

28.- CHEN Z, FU J, SHU Q, CHEN Y, HUA CH, LI F, et al. Diagnosis and treatment recommendations for pediatric respiratory infection caused by the 2019 novel coronavirus. World Journal of Pediatrics 2020; Feb 5. doi: 10.1007/s12519-020-00345-5. [Epub ahead of print].

29.- WHO. Clinical management of severe acute respiratory infection (SARI) when COVID-19 disease is suspected. Interim guidance. 13 March 2020. https://www.who. int/publications-detail/clinical-management-of-severeacute-respiratory-infection-when-novel-coronavirus(ncov)-infection-is-suspected (accedido el 3 de mayo de 2020).

30.- BRODIN P. Why is COVID-19 so mild in children? Acta Paediatr. 2020 Mar 25. doi: 10.1111/apa.15271. [Epub ahead of print].

31.- PAHO \& WHO. Laboratory Guidelines for the Detection and Diagnosis of COVID-19 Virus Infections. March 30, 2020. Disponible en: https://www.paho.org/ en/documents/laboratory-guidelines-detection-anddiagnosis-covid-19-virus-infection.

32.- Patel R, Babady E, Theel ES, Storch GA, Pinsky BA, St George K, et al. Report from the American Society for Microbiology COVID-19 COVID-19: Value of Diagnostic Testing for SARS-CoV-2/COVID-19. mBio 2020; 11: e00722-20. Disponible en: https://doi.org/ DOI: $10.1128 / \mathrm{mBio} .00722-20$.

33.- ZOU L, RUAN F, HUANG M, LIANG L, HUANG H, HONG Z. SARS-CoV-2 Viral Load in Upper Respiratory Specimens of Infected Patients. N Engl J Med 2020. Disponible en: https://doi.org/10.1056/ NEJMc2000231.

34.- SOCIEDAD ESPAÑOLA DE ENFERMEDADES INFECCIOSAS Y MICROBIOLOGÍA CLÍNICA (2020). Documento de Posicionamiento de la SEIMC sobre el diagnóstico microbiológico de COVID-19. Disponible en: https://seimc.org/contenidos/documentoscientificos/recomendaciones/seimc-rc-2020-Posicionamiento_SEIMC_diagnostico_microbiologico_COVID19.

35.- EUROPEAN CENTRE FOR DISEASE PREVENTION AND CONTROL. (2020). An overview of the rapid test situation for COVID-19 diagnosis in the EU / EEA. April 1 1 ${ }^{\text {st }}, 2020$. Disponible en: https:// www.ecdc.europa.eu/sites/default/files/documents/
Overview-rapid-test-situation-for-COVID-19-diagnosis-EU-EEA.pdf.

36.- HUANG C, WANG Y, LI X, REN L, ZHAO J, HU $\mathrm{Y}$, et al. Clinical features of patients infected with 2019 novel coronavirus in Wuhan, China. Lancet 2020; 395 (10223): 497-506. Disponible en: https://doi. org/10.1016/S0140-6736(20)30183-5.

37.- XIA W, SHAO J, GUO Y, PENG X, LI Z, HU D. Clinical and $\mathrm{CT}$ features in pediatric patients with $\mathrm{CO}$ VID-19 infection: different points from adults. Pediatric Pulmonology 2020; 55 (5): 1169-74. Disponible en: https://doi.org/10.1002/ppul.24718.

38.- SHEN K, YANG Y, WANG T, ZHAO D, JIANG Y, JIM R, et al. Diagnosis, treatment, and prevention of 2019 novel coronavirus infection in children: experts' consensus statement, World J Pediatr 2020; 1-9. doi: 10.1007/s12519-020-00343-7 [Epub ahead of print].

39.- CALVO C, GARCÍA M, DE CARLOS VICENTE JC, VÁSQUEZ MARTÍNEZ JL. Recomendaciones sobre el manejo clínico de la infección por el "Nuevo coronavirus" SARS-CoV2 Grupo de Trabajo de la Asociación Española de Pediatría (AEP). An Pediatr (Barc) 2020; 92 (4): 241.e1-241.e11. Disponible en: https://doi. org/10.1016/j.anpedi.2020.02.001.

40.- SANKAR J, DHOCHAK N, KABRA SK, LODHA R. COVID-19 in Children: Clinical Aproach and Management. Indian J Pediatr 2020; 1-10. doi: 10.1007/ s12098-020-03292-1.

41.- SOCIEDAD CHILENA DE INFECTOLOGÍA, Rama de Cuidados Intensivos Pediátricos, Recomendaciones de Manejo Farmacológico en Pacientes Pediátricos con Infección por SARS-CoV-2 (COVID-19) Disponible en: http://www.sochinf.cl/portal/templates/sochinf2008/ documentos/2020/Recomendaciones_terapia_COVID19_ninos.pdf.

42.- ORGANIZACIÓN MUNDIAL DE LA SALUD. Prevención y Control de Infecciones durante la atención sanitaria de casos en los que se sospecha una infección por el Nuevo coronavirus (nCoV) Orientaciones provisionales, 25 de enero 2020. Disponible en: https://apps.who int/iris/bitstream/handle/10665/330685/9789240001114spa.pdf.

43.- MARRARO GA, SPADA C. Consideration of the respiratory support strategy of severe acute respiratory failure caused by SARS-CoV-2 infection in children[J]. CJCP 2020, 22: 183-94.

44.- SCHEU C, DIETTES A, WEGNER A, BRAVO P, DRAGO M, NALEGACH M, et al. Guía de recomendaciones para manejo de pacientes pediátricos cursando COVID-19 grave. Sociedad Chilena de Pediatría, Rama de Cuidados Intensivos Pediátricos, versión 2.0, abril 2020.

45.- MARTÍNEZ S, MATURANA D, RIQUELME H, BUSTOS F, MOLINA P, GODOY S, et al, División de kinesiología intensiva pediátrica. Guía de recomen- 
daciones para la implementación de soporte respiratorio pediátrico en COVID-19. Disponible en: https://sochipe. $\mathrm{cl} / \mathrm{v} 3 /$ covid/24.pdf.

46.- TORRES R, VERONESI M, ARELLANO D, GROSS P, GUTIÉRREZ R, RESGUARDO A, et al. Recomendaciones clínicas de kinesiología respiratoria en atención de pacientes con COVID-19. Disponible en: https:// www.researchgate.net/publication/340608875_Guia_ de_recomendaciones_clinicas_de_kinesiologia_respiratoria_en_atencion_de_pacientes_con_COVID-19.

47.- CHEN H, GUO J, WANG CH, LUO F, YU X, ZHANG W, et al. Clinical characteristics and intrauterine vertical transmission potencial of COVID-19 infection in nine pregnant women: a retrospective review of medical records. Lancet 2020; 395: 809-15. Disponible en: https://doi.org/10.1016/ S0140-6736(20)30360-3.

48.- CENTERS FOR DISEASE CONTROL AND PREVENTION. Disponible en: https://espanol.cdc. gov/coronavirus/2019-ncov/need-extra-precautions/ pregnancy-breastfeeding.html

49.- CDC. Use personal protective equipment (PPE) when caring for patients with confirmed or suspected COVID-19. Use https://www.cdc.gov/coronavirus/2019

50.- SUNDARAN M, RAVIKUMAR N, BANSAL A, NALLASAMY K, BASAVARAJA GV, LODHA R, et al. Novel Coronavirus 2019 (2019-nCoV) Infection: Part II-Respiratory Support in the Pediatric Intensive Care Unit in Resource-limited Settings. Indian Pediatrics 2020; 57: 335-42.

51.- MELLADO R, FERRANDO C, MARTÍNEZ G. PNT Soporte Respiratorio en Pacientes COVID-19, Servicio de Anestesiología y Reanimación, Hospital Clínico de Barcelona. Disponible en: https://anestesiar.org/WP/ uploads/2020/03/Soporte-ventilatorio-en-pacientesCOVID-19-Hospital-C1\%C3\%ADnico-de-Barcelona. pdf.

52.- MATAVA C, KOVATSIS P, SUMMERS JL, CASTRO P, DENNING S, YU J, et al. Pediatric Airway Management in Coronavirus Disease 2019 Patients: Consensus Guidelines from the Society for Pediatric Anesthesia's Pediatric Difficult Intubation Collaborative and the Canadian Pediatric Anesthesia Society. Anesth Analg 2020; 10.1213. doi: 10.1213/ ANE.0000000000004872.

53.- CANELLI R, CONNOR CW, GONZÁlEZ M, NOZARI A, ORTEGA R. Barrier enclosure during endotracheal intubation. N Engl J Med 2020; 382 (20): 1957-8. Disponible en: https://doi.org/10.1056/ nejmc2007589.

54.- DIECKMANN P, TORGEIRSEN K, QVINDESLAND SA, THOMAS L, BUSHELL V, ERSDAL HL. The use of simulation to prepare and improve responses to infectious disease outbreaks like COVID-19: practical tips and resources from Norway, Denmark, and UK. Advances in Simulation 2020; 5: 3. Disponible en: https://doi.org/10.1186/s41077-020-00121-5.

55.- PEDIATRIC ACUTE RESPIRATORY DISTRESS SYNDROME. Consensus Recommendations From the Pediatric Acute Lung Injury Consensus Conference, The Pediatric Acute Lung Injury Consensus Conference Group. Pediatric Crit Care Med 2015; 16 (5): 428-39. Doi:10.1097/PCC.0000000000000350.

56.- KNEYBER M, MEDINA V, MODESTO V, BLOKPOEL R, BRIERLEY J, CHIDINI G. Practice recommendations for the management of children with suspected or proven COVID-19 infections from the Paediatric Mechanical Ventilation Consensus Conference (PEMVECC) and the section Respiratory Failure from the European Society for Paediatric and Neonatal Intensive Care (ESPNIC).PEMVECC COVID-19 recommendations. Disponible en: https://espnic-online.org/News/ Latest-News/Practice-recommendations-for-managingchildren-with-proven-or-suspected-COVID-19.

57.- GATTINONI L, CHIUMELLO D, CAIRONI P, BUSANA M, ROMITTI F, CAMPOROTA L. COVID-19 pneumonia: different respiratory treatment for different phenotypes?, Intensive Care 2020, April 14. Disponible en: https://doi.org/10.1007/s00134-020-06033-2.

58.- EXTRACORPOREAL LIFE SUPPORT ORGANIZATION COVID-19 Interim Guidelines, A consensus document from an international group of interdisciplinary ECMO providers, Disponible en: https://www. elso.org/Portals/0/Files/pdf/guidelines $\% 20$ elso $\% 20$ covid $\% 20$ for $\% 20$ web_Final.pdf.

59.- ALHAZZANI W, MOLLER MH, ARABI YM, LOEB M, GONG M, FAN E, et al. Surviving Sepsis Campaign: Guidelines on the Management of Critically Ill Adult with Coronavirus Disease 2019 (COVID-19). Intensive Care Med 2020; 1-34. doi: 10.1007/s00134020-06022-5.

60.- GAUTRET P, LAGIER JC, PAROLA P, HOANG VT, MEDDEB L, MAILHE M, et al. Hidroxycloroquina and azithromycina as a treatment of COVID-19: results of an open-label non-randomized clinical trial. Journal of Antimicobial Agents. Disponible en: https://doi. org/10.1016/j.ijantimicag.2020.105949.

Correspondencia a:

Dr. Guillermo Zepeda Flores

Neumólogo Pediatra, Departamento de Pediatría y

Cirugía Infantil. Facultad de Medicina Universidad de

Chile. Hospital Roberto del Río. Santiago, Chile.

Email: gzepedaflores@uchile.cl 